\title{
Ketamine-induced biliary dilatation
}

INSERM

\section{Source}

INSERM. (1999). Orphanet: an online rare disease and orphan drug data base. Ketamineinduced biliary dilatation. ORPHA:293807

Ketamine-induced biliary dilatation is an acquired biliary tract disease caused by the abusive consumption of ketamine, which results in the fusiform dilatation of the common bile ducts (CBD) without obstructive lesions or dilatation of the intrahepatic biliary ducts. Possible manifestations of the underlying cholangiopathy include epigastric pain and impaired liver function. Severity of CBD dilatation appears to correlate with the duration of ketamine consumption and the condition has been reported to be reversible in abstinent patients. 